\title{
DISCURSO, HISTÓRIA E MEMÓRIA EM DUAS FOTOGRAFIAS DE LULA
}

\author{
Amanda Batista Braga \\ (Universidade Federal da Paraíba) \\ http://orcid.org/0000-0001-6026-5017
}

RESUMO:

É certo que as propostas teóricas e metodológicas apresentadas pela Escola francesa de Análise do Discurso não se dão a ver de modo homogêneo ou a salvo de qualquer turbulência desde o final da década de 60. Nesse sentido, propomos empreender, neste artigo, uma discussão em torno dos deslocamentos pelos quais passaram as noções de história e memória no interior da disciplina desde sua fundação, em 1969, com vistas a discutir a operacionalização e a produtividade dessas noções tais como elas se apresentam atualmente. Para tanto, analisaremos duas fotografias de Lula, uma de 1979 e outra de 2018, entre as quais é possível vislumbrar o funcionamento de uma memória das imagens na construção discursiva de um líder popular, bem como a emergência de acontecimentos em suas singularidades no interior da pluralidade dos tempos históricos.

PALAVRAS-CHAVE: discurso, história, memória, Lula.

\section{DISCOURSE, HISTORY AND MEMORY IN TWO PHOTOS OF LULA}

\section{ABSTRACT:}

It is true that the theoretical and methodological proposals presented by the French School of Discourse Analysis do not give a homogeneous or safe view of any turbulence since the late 1960s. In this sense, we propose to undertake, in this paper, a discussion about the displacements through which the notions of 
history and memory have passed within the subject since its foundation in 1969, in order to discuss the operationalization and productivity of these notions as they currently are. To do so, we will analyze two photographs of Lula, one from 1979 and one from 2018, among which it is possible to glimpse the functioning of a memory of images in the discursive construction of a popular leader, as well as the emergence of events in their singularities within the plurality of historical times.

KEYWORDS: discourse, history, memory, Lula.

\section{1 lntrodução}

A relação entre língua e história, da qual deriva o trabalho da memória na instância da língua é, certamente, a mais crucial relação empreendida pela Análise do Discurso. Trata-se de uma articulação proposta já em 1969, com a publicação do livro Análise automática do discurso, de Michel Pêcheux, e da qual não se abrirá mão nas décadas seguintes. Para melhor compreender o modo como se propõe a articulação entre língua, história e memória no interior da disciplina e, do mesmo modo, colocar à prova sua capacidade analítica atualmente, propomos, neste artigo, uma discussão em duas etapas: primeiramente, uma apresentação do modo como as noções de história e memória foram propostas e posteriormente deslocadas no interior da Análise do discurso, chegando ao modo como essas mesmas noções podem, hoje, ser operacionalizadas. Em seguida, propõe-se um exercício de análise, no qual almeja-se fazer trabalhar as instâncias da história e da memória na materialização do discurso mediante a análise de duas fotografias de Lula, ambas em São Bernardo do Campo: a primeira, de 1979, durante a primeira greve geral dos metalúrgicos do país, e a segunda, de 2018, após o expresidente ter sua prisão decretada.

\section{A história na Análise do Discurso}

A aliança entre linguística e história é elemento fundante da Análise do Discurso. O livro intitulado Análise automática do 
discurso, publicado por Michel Pêcheux em 1969, já vislumbrava uma aliança entre linguistas e historiadores respaldada pelo conceito de discurso, responsável por suprir tanto a recusa da história em fazer trabalhar o significante linguístico, quanto a recusa da Linguística em fazer trabalhar o sujeito e a história enquanto instâncias que se materializam na língua. Não é, no entanto, a salvo de qualquer deslocamento que a noção de história se deu a ver ao longo do desenvolvimento da disciplina. Grosso modo, na tentativa de simplificar e objetivamente traçar seu percurso, poderíamos apresentá-lo como segue:

i) Num primeiro momento, submetida às concepções marxistas que dominaram o momento de constituição da Análise do Discurso, a noção de história se fazia presente mediante o conceito de condições de produção. Segundo Pêcheux (2014), o funcionamento de fenômenos linguísticos de dimensão superior à frase "não é integralmente linguístico, $[. .$.$] não podemos defini-lo senão em referência$ ao mecanismo de colocação dos protagonistas e do objeto do discurso, mecanismo que chamamos 'condições de produção' do discurso” (2014, p. 78). Nesse sentido, a dimensão histórica situava-se aqui no exterior linguístico, mais especificamente na conjuntura de interação em que os sujeitos do discurso se posicionam como tais, a partir de suas formações imaginárias e ideológicas;

ii) Em 1981, o conceito de condições de produção seria fortemente criticado por Jean-Jacques Courtine (2009), segundo o qual o mesmo se apresentaria apenas como a circunstância imediata de interação entre sujeitos: "é em campo fechado, na cena de teatro ou entre cordas do ringue, que se passam as peripécias discursivas, ao abrigo das determinações históricas" (COURTINE, 2009, p. 54). No intuito não apenas de atestar as restrições presentes no conceito de condições de produção, mas também, e principalmente, no intuito de reordená-lo, Courtine (2009) apontará a necessidade de uma análise histórica que comportasse as contradições ideológicas. $\mathrm{O}$ deslocamento da noção de história estaria, aqui, tanto na releitura do 
conceito de formação discursiva, cujas fronteiras receberiam certa elasticidade, na medida em que comportavam as relações contraditórias resultantes de sua heterogeneidade; quanto no conceito de enunciado divido que daí decorre, o qual denunciava a presença de duas formações discursivas no interior do mesmo enunciado. Pêcheux $(2009$, p. 25), ao prefaciar a obra de Courtine (2009), já anunciava que "essa heterogeneidade discursiva, feita de trechos e fragmentos, interessa na medida em que nela podem ser determinadas as condições concretas de existência das contradições pelas quais a história se produz". Do mesmo modo, nas palavras de Sargentini, têm-se que: "a afirmação de que todo conjunto de enunciados deve ser pensado como unidade dividida faz o conceito de história adentrar a análise dos enunciados, retirando-o da fronteira marginal a que estava submetido" (2010, p. 98);

iii) Em 1983, já em um momento de rupturas políticas na França, crise do marxismo, instauração da problemática da heterogeneidade do discurso e aproximação de Michel Pêcheux com autores da Nova História, Pêcheux (2008) volta-se às histórias singulares, arregimentadas pelo acontecimento discursivo. Numa análise do enunciado on $a$ gagné, o autor volta-se à particularidade com que se apresenta sua materialidade, à revelia das formas mais tradicionais de expressão política, bem como ao seu funcionamento e circulação: trata-se de um enunciado inscrito "na ordem do acontecimento, das séries discursivas, dos enunciados subterrâneos", alinhando-se à proposta da Nova História (SARGENTINI, 2010, p. 98). Trata-se, enfim, de não mais considerar a história à margem do discurso, como o fazia o conceito de condições de produção, mas de considerá-la no interior do próprio discurso.

Feitas tais pontuações, que partem do conceito de condições de produção, em 1969, e desaguam na leitura de Pêcheux da Nova História, durante a década de 80 , seria preciso, ainda, reconhecer que, ao final da década de 80 , no que concerne ao contexto francês, a 
Análise do Discurso assistiria a um apagamento da esfera histórica em detrimento de uma perspectiva exclusivamente linguística, o que representava uma redução, cada vez mais acentuada, do histórico ao sintático: "redução do histórico ao político, do político ao ideológico, do ideológico ao discursivo, do discursivo ao sintático", dizia Courtine em 1989 (2006, p. 56). Tratava-se, portanto, de uma gramaticalização do discurso, que tinha sua dimensão histórica arrefecida em benefício de uma descrição gramatical, uma caracterização dos diferentes níveis de funcionamento linguístico de um texto. Em detrimento dessa perspectiva, Courtine, já numa leitura claramente próxima dos trabalhos de Michel Foucault, apontaria a necessidade de "pensar e descrever a maneira como se entrecruzam regimes de práticas e séries de enunciados; e rearticular a perspectiva do linguista e a do historiador" (COURTINE, 2006, p. 57). É nessa perspectiva, ancorada nas propostas de Foucault, que a Análise do Discurso parece encontrar fôlego, atualmente, nos trabalhos desenvolvidos no Brasil.

Segundo Sargentini, Foucault é um filósofo que, "ao dialogar com os historiadores (ao mesmo tempo rejeitado por uns e admirados por outros), combate uma história feita de causalidades e continuidades, questiona dogmas, duvida da verdade dos fatos" (2010, p. 99). Tal postura, pulverizada por toda obra foucaultiana, parece-nos bem representada, por exemplo, pela noção de a priori histórico em sua relação com os enunciados e com os discursos, figurando aí como a própria "condição de realidade dos enunciados", como "as condições de emergência dos enunciados, a lei de sua coexistência com outros, a forma específica de seu modo de ser, os princípios segundo os quais subsistem, se transformam e desaparecem" (FOUCAULT, 2010, p. 144). Trata-se de uma proposta que considera a materialidade dos enunciados no interior dos quadros formais em que emerge, alheia às verdades invariáveis, trans-históricas e, ao mesmo tempo, às generalizações operadas por uma história tradicional. Ao contrário disso, o a priori histórico "tem de dar conta do fato de que o discurso não tem apenas um sentido ou uma verdade, mas uma história" (FOUCAULT, 2010, p. 144). 


\section{A memória na Análise do Discurso}

Uma vez feita essa breve digressão a respeito do tratamento que a noção de história assumiu ao longo do desenvolvimento da Análise do Discurso, seria preciso, do mesmo modo e ainda pontualmente, caracterizar aquilo que a disciplina entendeu como sendo não simplesmente o trabalho da história na instância da língua, mas especificamente o trabalho da memória, isto é, a retomada de construções anteriores no momento próprio de materialização dos discursos. Ainda grosso modo, poderíamos caracterizar como segue:

i) Em 1969, com a publicação de Análise automática do discurso, conforme referimos anteriormente, Pêcheux postulava certa aliança entre linguistas e historiadores, no entanto, é apenas com a publicação de Semântica $e$ discurso, em 1975, que se torna visível a incidência da memória na estrutura da língua por meio do conceito de interdiscurso: "o ponto nodal do sistema", segundo Maldidier (2011, p. 50). O interdiscurso, para Pêcheux (1997, p. 162), "reside no fato de que 'algo fala' (ça parle) sempre 'antes, em outro lugar e independentemente",, supondo, assim, a construção dos discursos a partir de dados anteriores, já ditos e esquecidos. Como pontos de apreensão do funcionamento do interdiscurso, o mesmo é pensado em sua articulação com o pré-construído e com o intradiscurso. O primeiro, nas palavras do próprio Pêcheux (1997, p. 164), "corresponde ao 'sempre-já-aí da interpelação ideológica que fornece-impõe a 'realidade' e seu 'sentido' sob a forma da universalidade". Dito de outro modo, o pré-construído corresponde ao encaixe sintático no qual é possível flagrar a presença de elementos exteriores à asserção, isto é, a presença de dados anteriores, de construções já-ditas, agora retomadas sob a forma de evidência (como nas orações subordinadas adjetivas explicativas, por exemplo). $\mathrm{O}$ intradiscurso, por sua vez, corresponde ao "funcionamento do discurso com relação a si mesmo (o que eu digo agora, com relação ao que eu disse antes e ao que eu direi depois [...])" (PÊCHEUX, 1997, p. 166). Em sua articulação com o interdiscurso, o intradiscurso corresponderia o eixo da 
formulação material do discurso, ao tempo em que o interdiscurso corresponderia ao eixo da sua constituição. É no interdiscurso - eixo da constituição - que residem todos os dizeres já ditos e esquecidos, do mesmo modo que é no intradiscurso - eixo da formulação - que estão os dizeres materialmente realizados, em condições dadas;

ii) Já na década de 80 , o trabalho do interdiscurso/ intradiscurso receberia, agora, nos textos de Pêcheux, a denominação de memória discursiva. Tanto em Papel da memória quanto em Discurso: estrutura ou acontecimento, ambos de 1983, está impressa uma preocupação com as condições em que a singularidade de um acontecimento histórico se inscreve em um espaço de memória. Para Pêcheux, "a memória discursiva seria aquilo que, face a um texto que surge como acontecimento a ler, vem restabelecer os 'implícitos' (quer dizer, mais tecnicamente, os préconstruídos, elementos citados e relatados, discursostransversos de que sua leitura necessita: a condição do legível em relação ao próprio legível (PÊCHEUX, 2007, p. 52). É essa memória discursiva, discute Pêcheux (2007), que trabalharia em prol de um efeito de série no interior de um dado discurso, produzindo uma regularização, ou uma repetição, que estaria suscetível ao desmoronamento sob o peso do acontecimento, isto é, sob o peso da singularidade promovida pelo acontecimento: "o acontecimento, no caso, desloca e desregula os implícitos associados ao sistema de regularização anterior" (PÊCHEUX, 2007, p. 52). Semelhante discussão é encontrada em Discurso: estrutura ou acontecimento, quando o autor, fazendo uma radiografia da então situação política francesa, e particularmente da atuação da mídia nesse cenário, parte do acontecimento discursivo sintetizado no enunciado on a gagné para demonstrar como o mesmo evoca, em um espaço de memória, o grito da torcida em estádios de futebol;

iii) Ainda na década de 80, trazendo Michel Foucault definitivamente pra Análise do Discurso, Jean-Jacques Courtine (2009) também proporia, à esteira do conceito de 
enunciado foucaultiano, um conceito de memória discursiva. Em A arqueologia do saber (1969), Foucault apresenta um conceito de enunciado demarcado por quatro características, sendo a terceira delas a existência de um domínio associado, constituído "pela série das outras formulações, no interior das quais o enunciado se inscreve e forma um elemento", bem como "pelo conjunto das formulações a que o enunciado se refere (implicitamente ou não), seja para repeti-las, seja para modificá-las ou adaptálas, seja para se opor a elas, seja para falar de cada uma delas; não há enunciado que, de uma forma ou de outra, não reatualize outros enunciados" (FOUCAULT, 2010, p. 111). É dessa relação que o enunciado estabelece com os demais enunciados que povoam suas margens que Courtine (2009, p. 105-106) destaca a produção de efeitos de memória, definindo-a enquanto "existência histórica do enunciado no interior das práticas discursivas". Com isso, Courtine (2009) está levantando a problemática da duração (à esteira de Braudel [1990]) e da pluralidade dos tempos históricos em relação à natureza desse enunciado. "A introdução da noção de 'memória discursiva' em AD nos parece, assim, colocar em jogo a articulação dessa disciplina com as formas contemporâneas da pesquisa histórica, que insistem no valor a ser atribuído à longa duração" (COURTINE, 2009, p. 105).

Essas breves caracterizações, tanto do modo como a história, quanto do modo como a memória foram entendidas em diferentes momentos da Análise do Discurso, apesar da simplicidade com que se apresentam os quadros, permitem-nos acessar certo trajeto percorrido pela disciplina ao longo de pelo menos 3 décadas: a) a aliança entre o trabalho do linguista e do historiador proposta por Pêcheux em 1969, mediante o conceito de condições de produção; b) a abordagem oferecida pelo autor, em 1975, à incidência de dados construídos anteriormente na então materialidade dos discursos, por meio dos conceitos de interdiscurso, intradiscurso e pré-construído; c) a crítica feita por Courtine, em 1981, ao conceito o de condições de produção e, ao mesmo tempo, seu encaminhamento às análises das relações contraditórias decorrentes da heterogeneidade das 
formações discursivas, concomitantemente à sua proposição do conceito de memória discursiva, à esteira de Foucault; d) o enfim encontro de Michel Pêcheux com Michel Foucault, em 1983, quando Pêcheux se aproxima da Nova história e assume também o termo memória discursiva na análise da singularidade dos acontecimentos; e) e, por fim, as demandas atuais da Análise do Discurso, as quais referenciamos a partir da noção foucaultiana de a priori histórico, abrindo a possibilidade de fazer trabalhar não apenas os efeitos de memória entre enunciados, como propõe Courtine, mas também uma história que abre mão das verdades universais e das generalizações banalizantes em prol de uma perspectiva que esteja voltada à análise dos enunciados em suas raridades.

Há, assim, entre o surgimento da disciplina, ao final da década de 60 , e os dias atuais, um crescendum continuum em direção a questões como a incidência da memória na constituição dos discursos, a heterogeneidade discursiva, o diálogo com a Nova História, os trabalhos então desenvolvidos por Michel Foucault, a análise dos enunciados enquanto acontecimentos singulares e, do mesmo modo, a preocupação com uma materialidade discursiva que não mais se reduzia à linguagem verbal. É esse último ponto que gostaríamos de discutir agora, a fim de concluir esta etapa do artigo.

A inquietação da Análise do Discurso em torno das materialidades que extrapolam a linguagem verbal - tais como a imagética, a sonora e a gestual -, têm início na década de 80 . É este o momento em que os textos de Michel Pêcheux ${ }^{1}$, preocupados com a mutação pela qual passava o próprio discurso político, seu objeto primeiro, estão voltados ao empreendimento de uma análise dos enunciados em sua natureza sincrética. Tal mutação deflagrava a convergência de signos da publicidade no interior da fala política, provocando um rompimento com seus modos mais tradicionais de expressão. "Em suma, trata-se das núpcias entre Marx e a Coca-Cola [...], um recobrimento das discursividades políticas tradicionais pelas formas breves, vivas e efêmeras do discurso publicitário" (COURTINE, 2011, p. 147). Nesse cenário, as esferas da mídia e do

1 Delimitações, inversões e deslocamentos (1990), Papel da memória (2007), Discurso: estrutura e acontecimento (2008). 
mercado fariam funcionar, de modo cada vez mais acelerado, uma midiatização do discurso político, ou, ainda, sua espetacularização, segundo a fórmula de Guy Debord (1997): vislumbrava-se "uma verdadeira revolução áudio-visual, com a exponencial da mídia que instalava o reinado das imagens, dos textos sincréticos que amalgamam diversas materialidades (linguísticas e visuais)" (GREGOLIN, 2008, p. 27).

O papel exercido pelas novas mídias e tecnologias audiovisuais no processo de produção e circulação de textos sincréticos aguçaria, de modo definitivo, a necessidade de explorar o funcionamento e a produção de sentidos das imagens. É partindo dessa preocupação que Courtine (2013) propõe, à esteira do conceito de memória discursiva, a noção de intericonicidade, a qual será basilar no empreendimento de uma análise que busque tanto resgatar a dimensão histórica dos discursos, quanto considerá-los em sua integridade material. Para circundá-la, Courtine (2013) parte da ideia de que a imagem, além de um modelo de língua, é um modelo de discurso, o que levar-nos-ia a considerar que a imagem mantém com a memória a mesma relação que um discurso verbalmente materializado mantém. Se os discursos são perpassados por memórias, o mesmo acontece com as imagens: "toda imagem se inscreve em uma cultura visual, e essa cultura visual supõe a existência junto ao indivíduo de uma memória visual, de uma memória das imagens onde toda imagem tem um eco. Existe um 'sempre já' da imagem" (COURTINE, 2013, p. 43).

O que Courtine (2013) defende, com isso, é que seria possível a proposição de uma arqueologia das imagens construída no encontro entre a história das imagens vistas e a história das imagens sugeridas. Assim, a noção de intericonicidade coloca em jogo a relação entre imagens que são internas e igualmente externas ao sujeito: um permanente diálogo entre as imagens que inventariamos individualmente e as imagens que nos são oferecidas pela cultura visual.

A intericonicidade supõe, portanto, relacionar conexões de imagens: imagens exteriores ao sujeito, como quando uma imagem pode ser inscrita numa série de imagens, uma arqueologia, à maneira do enunciado numa rede de formulações junto à Foucault; mas também imagens internas, que supõem a consideração de todo o catálogo memorial da 
imagem junto ao indivíduo, e talvez também os sonhos, as imagens vistas, esquecidas, ressurgidas ou até fantasiadas, que assombram o imaginário (COURTINE, 2013, p. 44).

É através da circulação dessas intericonicidades que a grande mídia, por exemplo, brinca com a memória, construindo sentidos mediante um jogo que parte da tradição e faz irromper novos discursos. Vicissitudes da mídia, sentidos da história, imagens que se cruzam: entre o dado e o novo, a intericonicidade aparece como um clarão, lançando luz sobre a produção de sentidos no interior de uma cultura visual. Seus frutos estão produzidos na instantaneidade e na singularidade de um acontecimento discursivo, conforme veremos a seguir.

\section{História e memória na Análise do discurso hoje: uma memória das imagens em duas fotografias de Lula}

O medo que se tem do Lula é o medo que se tem do povo. (Leonardo Boff)

Em abril de 2018, após ter sido condenado em segunda instância e ter sua prisão decretada, Lula discursava em frente ao Sindicato dos Metalúrgicos do ABC, em São Bernardo do Campo. O primeiro enunciado que analisaremos é a fotografia feita por Francisco Proner $^{2}$, que flagra o momento em que o ex-presidente desce do carro de som e é carregado por uma multidão de apoiadores até a sede do Sindicato, de onde sairia momentos depois para se entregar à Polícia Federal. De todo material produzido e veiculado durante a mobilização, esta fotografia foi, sem dúvida, aquela que

\footnotetext{
${ }^{2}$ A referida fotografia não é apresentada neste trabalho por falta de autorização para fazê-lo, mas se trata de uma imagem que foi rápida e largamente difundida. Pode ser acessada em: $<$ https://pt.org.br/foto-do-abraco-a-lula-de-francisco-proner-e-escolhidaimagem-do-ano/>. Acesso em: 19 fev. 2019.
} 
mais circulou, nacional e internacionalmente ${ }^{3}$. Considerada, posteriormente, como uma das imagens do ano de $2018^{4}$, a fotografia guarda sua força não apenas pela sua capacidade de narrar o ápice de uma histórica mobilização política e popular, mas também pela sua capacidade de fazer emergir a memória de outra fotografia, produzidas quase 40 anos antes.

Figura 1 - Lula em 1979

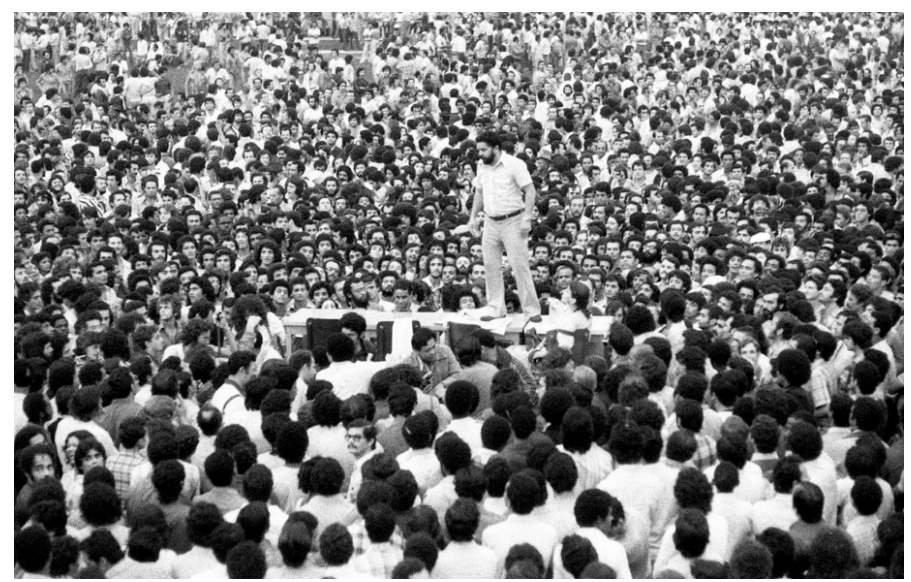

Fotografia: Fernando Pereira/ CPDoc JB

Em março de 1979, a mesma sede do Sindicato dos Metalúrgicos do $\mathrm{ABC}$ havia sido palco da primeira greve geral de uma categoria no país, desde a paralisação de Contagem (MG), em 1968: 200 mil metalúrgicos desafiavam a grande indústria automobilística da região e a repressão do governo militar. Diante da massiva adesão dos trabalhadores ao movimento, as assembleias deixaram de ser na sede do Sindicato para ser no Estádio Municipal

\footnotetext{
${ }^{3}$ A fotografia aparece em jornais como The New York Times, The Guardin e El Pais, quando da notícia da prisão de Lula.

4 Foto do abraço a Lula, de Francisco Proner, é escolhida imagem do ano. Disponível em: $\quad<$ https://pt.org.br/foto-do-abraco-a-lula-de-francisco-proner-eescolhida-imagem-do-ano/>. Acesso em: 19 fev. 2019.
} 
Vila Euclides, cedido pelo então prefeito da cidade. Neste segundo enunciado $^{5}$, também uma fotografia, tão histórica quanto a primeira, em cima de uma mesa de escritório improvisada enquanto palco, e sem qualquer sistema de som que pudesse amplificar e transmitir sua voz, Lula, cercado de trabalhadores, usava um megafone: aqueles que estavam próximos ao então sindicalista transmitiam suas palavras, em coro, aos que estavam mais afastados.

Entre os dois enunciados ou, ainda, entre o ex-presidente condenado da fotografia feita em 2018 e o metalúrgico sindicalista da fotografia de 1979, ambos cercados por uma imensa mobilização popular que os reconhece enquanto líderes, há "um fio tênue, mas tenaz, que atravessa e tece a teia das palavras e das imagens" (COURTINE, 2013, p. 24). Esse fio é a própria história, uma memória das imagens, o funcionamento da intericonicidade, e é justamente ele que justifica a massiva distribuição do primeiro enunciado quando da prisão de Lula, em abril de 2018.

Para fazer jus à espessura histórica que atravessa e é constitutiva dos enunciados aqui postos, poder-se-ia empreender uma análise que fizesse valer uma longa duração histórica e remetesse à própria construção discursiva do homo politicus, desde a Antiguidade Clássica. Na impossibilidade de fazê-lo num curto espaço, e por entender que esse esforço já tem sido feito alhures ${ }^{6}$, propõe-se partir da discussão empreendida por Courtine (2015) sobre o final do século XIX e o início do século XX (numa curta duração histórica, portanto): é esse momento histórico que nos possibilita abordar a emergência dos discursos sobre a multidão e seu líder, justamente porque é esse momento histórico que flagra o nascimento das grandes cidades e a emergência das sociedades de massa. É no século XIX que as grandes aglomerações humanas fariam emergir a multidão enquanto acontecimento histórico e objeto de pensamento, acerca das quais seriam postas questões até então inéditas: como dominar o poder e a fúria das multidões, como convencê-las e guiálas?

\footnotetext{
${ }^{5}$ Foto do acervo do Jornal do Brasil, gentilmente cedida para este trabalho.

${ }^{6}$ No Brasil, diversos trabalhos acerca do discurso político em sua dimensão histórica têm sido realizados e publicados pelo Laboratório de Estudos do Discurso (UFSCar), coordenado pela Professora Vanice Sargentini e pelo Professor Carlos Piovezani. Na França, Jean-Jacques Courtine o faz desde o final da década de 80.
} 
Retomando as obras de Le Bon (1896) e de Emile Zola (1968), Courtine (2015) mostrará que surge, aqui, uma caracterização da multidão assentada em um modelo arcaico de dominação: as multidões seriam femininas e seu estado psicológico perpassaria sentimentos como "a impulsividade, a irritabilidade, a inconstância, os exageros e simplificações dos sentimentos, a credulidade", ou, ainda, a irracionalidade e a imprevisibilidade (COURTINE, 2015, p. 266). Pelo mesmo motivo - o modelo de dominação -, presume-se a necessidade de um líder. Mais que isso: um líder carismático que não apenas seja oriundo da multidão, posto que "a voz do povo emerge do corpo do povo" (COURTINE, 2015, p. 281), mas que também fale em seu nome e a seu modo, fazendo surgir uma eloquência proletária que marca o distanciamento da fala pública dos manuais de retórica e uma aproximação da mesma com a rusticidade do trabalho manual.

Tal rusticidade, que marcaria a fala pública do líder justamente porque é também ela que marca a fala da multidão da qual ele se origina, selaria "um antigo, consolidado e duradouro imaginário sobre a voz do povo. A multidão vocifera, protesta, geme ou delira - de raiva ou de prazer: a massa não fala" (COURTINE, 2015, p. 271). O povo, nesse sentido, colocaria em xeque a estabilidade da clássica organização das cenas oratórias, nas quais o orador detém o poder da palavra diante de uma multidão silenciosa. A voz do povo não se situa nem no silêncio e nem tampouco na articulação da fala: sua expressão está, antes, em murmúrios e burburinhos coletivos, em explosões nervosas e inflamadas emoções.

É nesse cenário, que engloba uma multidão enfurecida $\mathrm{e}$, ao mesmo tempo, um líder eleito e construído à sua imagem e semelhança, que se dá a tentativa de fechamento das massas: uma domesticação ou uma gestão das grandes populações, tal qual discutiu Foucault (2008) em relação à governamentalidade. A formação de partidos políticos é um exemplo desse processo.

Se voltamos, então, aos enunciados apresentados incialmente, resta evidente que os discursos que estão presentes e que compõem tais enunciados não estão presos ao momento histórico em que foram produzidos. Ao contrário disso, a construção discursiva do líder popular, que não apenas fala pelo povo como também se origina dele - presente em ambos enunciados - está posto em uma duração que remete, pelo menos, ao século XIX, sendo necessária, portanto, uma 
retomada desse a priori histórico na leitura dos enunciados em suas emergências singulares.

O enunciado em que está retratado o Lula sindicalista, produzido no auge da greve dos metalúrgicos, em 1979, flagra mais do que seu pronunciamento em um estádio esportivo. O enunciado flagra o próprio fechamento de uma massa que estava, até ali, dispersa sob a forma de minorias em greve. $\mathrm{O}$ enunciado flagra, além disso e principalmente, o nascimento de seu líder, o qual, assim como o previu Le Bon (1896), não apenas emergiu da própria multidão como também, em seu corpo, carrega os traços do trabalho manual: seus gestos corporais, sua roupa informal, sua barba, seus cabelos, ressoam a brutalidade do trabalho operário.

O enunciado que retrata o Lula ex-presidente, por sua vez, quase 40 anos além, flagra o retorno das multidões às ruas, agora não mais para escolha e reconhecimento de seu líder, mas para defesa da sua história. Por um lado, bem como na fotografia anterior, ainda que a imagem tenha sido produzida em outro ângulo, a organização dos indivíduos se dá de modo análogo: uma imensa multidão em torno de Lula, ao centro da imagem. Por outro lado, ao contrário da fotografia anterior, em que Lula estava em cima de uma mesa, aqui, o ex-presidente está, literalmente, nos braços do povo, mistura-se e confunde-se com ele, num apagamento dos limites individuais e das distâncias que os separam, porque agora, mais do que nunca, é preciso ratificar sua origem.

Não é aleatória, portanto, a ida de Lula ao Sindicato momentos antes de sua prisão, tampouco é aleatória a escolha da fotografia que viria a ser reproduzida em escala global. O que está em jogo, na singularidade daquele acontecimento, é a retomada de uma memória que atualiza a história da construção de um líder popular. Tal análise, no entanto, não seria possível se lançássemos mão apenas do conceito de condições de produção, no qual a história não aparece materializada no próprio enunciado, ou mesmo se lançássemos mão de conceitos que supõem o trabalho da memória materializado apenas linguisticamente, como na descrição do préconstruído. Uma análise dessa natureza requer, justamente, a consideração dos enunciados enquanto acontecimentos singulares, a retomada de sua espessura histórica em diferentes durações e, enfim, a aplicação de conceitos que tratem o enunciado para além de sua materialidade linguística, como é o caso da intericonicidade. 


\section{Considerações finais}

Embora possa parecer um tanto comum falar sobre história e memória no interior dos estudos do discurso e, particularmente, no interior da Escola francesa de Análise do discurso, esta é uma tarefa que exige um olhar retrospectivo para os diferentes modos com que essas instâncias foram tratadas pela disciplina. Partindo desse pressuposto é que propomos apresentar, neste artigo, mesmo simplificadamente, as noções de história e memória que foram propostas e operacionalizadas pela Análise do discurso desde sua fundação, em 1969.

Por um lado, no que se refere à noção de história, partimos do conceito de condições de produção, proposto por Pêcheux em 1969, e chegamos à aliança do autor com a Nova história, na década de 80 , bem como à noção de a priori histórico, proposta por Michel Foucault. Por outro lado, no que concerne à noção de memória, partimos dos conceitos de interdiscurso, intradiscurso e préconstruído, propostos por Pêcheux em 1975, e desaguamos nos conceitos de memória discursiva e intericonicidade, construídos por Courtine. Em suma, aponta-se para uma análise comprometida com o trabalho da história e da memória na produção dos enunciados enquanto acontecimentos singulares, despidos de verdades que atravessam o tempo e de generalizações de toda ordem; uma análise comprometida, ainda, com a pluralidade dos tempos históricos resgatada em materialidades que se mostra cada vez mais sincréticas, ou liquefeitas, tal como o demonstramos mediante a análise das fotografias de Lula.

\section{REFERÊNCIAS}

BRAUDEL, Fernand. História e ciências sociais. 6. ed. Lisboa: Presença, 1990.

COURTINE, Jean-Jacques. Metamorfoses do discurso político: derivas da fala pública. Tradução de Carlos Piovezani e Nilton Milanez. São Carlos: Claraluz, 2006.

COURTINE, Jean-Jacques. Análise do Discurso: o discurso comunista endereçado aos cristãos. Tradução de Bacharéis em Letras 
pela Universidade Federal do Rio Grande do Sul. São Carlos: EdUFSCar, 2009.

COURTINE, Jean-Jacques. Discurso e imagens: para uma arqueologia do imaginário. Tradução de Carlos Piovezani. In: PIOVEZANI, Carlos; CURCINO, Luzmara; SARGENTINI, Vanice. (Org.). Discurso, semiologia e história. São Carlos: Claraluz, 2011. p.145-162.

SARGENTINI, Vanice. Decifrar o corpo: pensar com Foucault. Tradução de Francisco Morás. Petrópolis: Vozes, 2013.

SARGENTINI, Vanice. A voz do povo: a fala pública, a multidão e as emoções na aurora da era das massas. In: COURTINE, JeanJacques; PIOVEZANI, Carlos. (Org.). História da fala pública: uma arqueologia dos poderes do discurso. Petrópolis: Vozes, 2015. p. 261-289.

DEBORD, Guy. A sociedade do espetáculo: comentários sobre a sociedade do espetáculo. Tradução de Estela dos Santos Abreu. Rio de Janeiro: Contraponto, 1997.

FOUCAULT, Michel. Segurança, território e população: curso dado no Collège de France (1977-1978). Tradução de Eduardo Brandão. São Paulo: Martins Fontes, 2008.

FOUCAULT, Michel. A arqueologia do saber. Tradução de Luiz Felipe Baeta Neves. 7 ed. Rio de Janeiro: Forense Universitária, 2010.

GREGOLIN, Maria do Rosário. J.-J. Courtine e as metamorfoses da Análise do Discurso: novos objetos, novos olhares. In: SARGENTINI, Vanice; GREGOLIN, Maria do Rosário. (Org.). Análise do Discurso: heranças, métodos e objetos. São Carlos: Claraluz, 2008. p. 21-37.

LE BON, Gustave. La psycologie des foules. Paris: Alcan, 1896.

MALDIDIER, Denise. A inquietude do discurso. Um trajeto na história da Análise do discurso: o trabalho de Michel Pêcheux. In: PIOVEZANI, Carlos; SARGENTINI, Vanice. (org.). Legados de Michel Pêcheux: inéditos em Análise do discurso. São Paulo: Contexto, 2011. p. 39-62. 
PÊCHEUX, Michel. Delimitações, inversões e deslocamentos. Caderno de estudos linguísticos, Campinas, v. 19, p. 7-24, jul./dez., 1990.

PÊCHEUX, Michel. Semântica e discurso: uma crítica à afirmação do óbvio. Tradução de Eni Pulcinelli Orlandi et al. 3. ed. Campinas: Editora da Unicamp, 1997.

PÊCHEUX, Michel. Papel da memória. In: ACHARD, Pierre et al. Papel da memória. Tradução de José Horta Nunes. 2. Ed. Campinas: Pontes, 2007.

PÊCHEUX, Michel. O discurso: estrutura ou acontecimento. Tradução de Eni P. Orlandi. 5 ed. Pontes: Campinas, 2008.

PÊCHEUX, Michel. O estranho espelho da Análise do Discurso. In: COURTINE, Jean-Jacques. Análise do Discurso: o discurso comunista endereçado aos cristãos. Tradução de Bacharéis em Letras pela Universidade Federal do Rio Grande do Sul. São Carlos: EdUFSCar, 2009. p. 21-26.

PÊCHEUX, Michel. Análise automática do discurso (AAD-69). In: GADET, Françoise; HAK, Tony. (Org.). Por uma análise automática do discurso: uma introdução à obra de Michel Pêcheux. Tradução de Bethania S. Mariani et al. 5. ed. Campinas: Editora da Unicamp, 2014. p. 59-158.

SARGENTINI, Vanice. As relações entre a Análise do Discurso e a História. In: MILANEZ, Nilton; GASPAR, Nádea Regina. (Org.). A (des)ordem do discurso. São Paulo: Contexto, 2010. p. 95-102.

ZOLA, Emile. Germinal. Paris: Garnier/ Flammarion, 1968.

Recebido em: 19/11/2019

Aceito em: 09/03/2020 